\title{
Two-way conductivity converters in the technology of tire cord rubberization
}

\author{
Rishat Ganiev ${ }^{1, *}$ \\ ${ }^{1}$ Kazan National Research Technological University, Institute of chemical technology, 423570 Avenue of Builders, 47, Nizhnekamsk, \\ Republic of Tatarstan, Russian Federation
}

\begin{abstract}
The article deals with the problems of increasing the multi-engine electric drive energy efficiency on the example of the cropped cord production line in manufacture of tires. There are requirements for line electric drives that can have an impact both each other and the overall power grid in the mode of technological braking, as well as the requirements for the availability of protection functions and mutual coordination with the mains supply. To solve this problem, options have been developed to build reversible frequency converters on fully controlled (locked) keys as part of frequency-regulated technological electric drives in the production of cord for car tires with energy recovery. The construction of the reversible frequency converter with the use of autonomous voltage inverters, as well as the results of computer simulations in the reactor and non-reactor circuits of reversible frequency converters in the composition of multi-motor electric drives with a total DC bus are shown.
\end{abstract}

\section{Introduction}

The relevance of the article is dictated by the mass production of rubberized cord, which is the most complex and energy-intensive technological operation that determines the performance and energy consumption in the manufacture of automobile tires. The solution of such complex problems on current production involves the use of multi-frequencyadjustable electric drive, which can meet the requirements of static and dynamic properties of each actuator production lines separately, and the whole of the electrical installation as a whole. The new requirements require compliance with the standards and regulations established by the International Electrotechnical Commission (IEC) regarding the electromagnetic compatibility of electric drives with the mains supply. Systems that meet the requirements of modern production are based on the principles of energy interaction of technological electric drives with the mains supply. The need for active power consumption makes the converter in the consumer useful (active) power network login and, if necessary, improve the network power factor in the compensator passive components of the power generated by other loads. $[1,2,3,4,5]$.

\section{Relevance of inverter problem and it's solution}

To date, most electric drives of cord lines do not meet the specified requirements. Their operation is associated with the problem of compensating a significant amount of reactive power, as well as the power generated in the network of higher harmonics current.. In addition, there is a need to improve the energy efficiency of electric drives due to the mutual influence between drives working on a distributed mechanical load. The solution can be the use of reversible frequency converters (RFC), shown in $[5,6,7,8]$. RFC help to avoid unproductive power consumption at all stages of the technological cycle, including at intervals of regenerative braking of electric drives. In the circuit of an electric drive with a reversible converter, the recovery process is accompanied by the conversion of the accumulated kinetic energy of the fabric rolls of cord into electrical energy, which can be used to feed other inverters in the cord line or returned to the mains supply. [2,9] Thus, we need to design the electric lines with the possibility of recovery into the braking drives general power supply, having functions of protection and mutual agreement with each other and with the mains supply.

\section{RFC Converter structures}

Let's consider the options of RFC performance in electric drives of the cord lines. The performance of RFC can be a variant with the use of a modern element base (one or two-operational thyristors, as well as power transistor switches) based on one or two-link frequency converters. The most interesting option is a frequency-controlled drive based on two-link RFC with autonomous current inverters (ACI) (a) and autonomous voltage inverters (AVI) (b), shown in Fig. 1.

\footnotetext{
* Corresponding author: n7007@mail.ru
} 


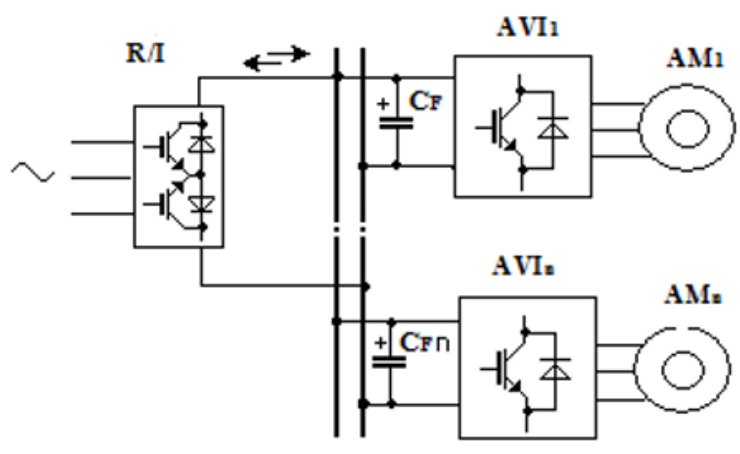

Fig. 1. Versions of a multi-motor drive AVI scheme with a common rectifier $(\mathrm{R} / \mathrm{I})$, inverter (I) and a common filter capacitors $\left(\mathrm{C}_{\mathrm{F}} \ldots \mathrm{C}_{\mathrm{Fn}}\right)$.

Despite the circuit differences, the variants implement the same principle of structural construction of a multi-motor electric drive, which consists of several $(n \geq 1)$ self-contained inverters from the total DC tires with the only primary power source for all drives of these tires in the form of rectification/inverting unit ( $\mathrm{R} / \mathrm{I})$. This decision is confirmed by thepatent of the utility model [10,11]. At the stage of comparative analysis the performanceof electric drives is considered both on the basis of ACI and on the basis of AVI. The choice of option is determined from the specific requirements of the mechanism and the method of regulating the asynchronous motor (AM). In turn, the design of the R/I block may also vary, depending on the selected element base and the number of valve sets in the RFC. The implementation of a two-link frequency converter based on ACI allows a single-component execution of block $\mathrm{R} / \mathrm{I}$, in schemes based on $\mathrm{AVI}_{1} \ldots$ $\mathrm{AVI}_{\mathrm{n}}$, this block must be two-component.[12]

\section{Modelling drives with reversible frequency converters}

\subsection{Electric drive with an autotransformer}

Shown in Fig.2 the power circuit of the model contains a source of three-phase mains voltage of $220 / 380 \mathrm{~V}$, made on single-operation thyristors; a rectification/ inverting unit with equalizing reactors; a DC link with a filter capacitor $\mathrm{C}_{\mathrm{f}}$; AVI made on transistor keys V1, ... V6, shunted by reverse diodes; an asynchronous motor (AM).

The purpose of the simulation is to consider the advantages and disadvantages of the existing version of the $\mathrm{R} / \mathrm{I}$, made on the basis of a two-part reversible converter with joint control in a reactor-free version.

In the presented model, the elimination of equalizing

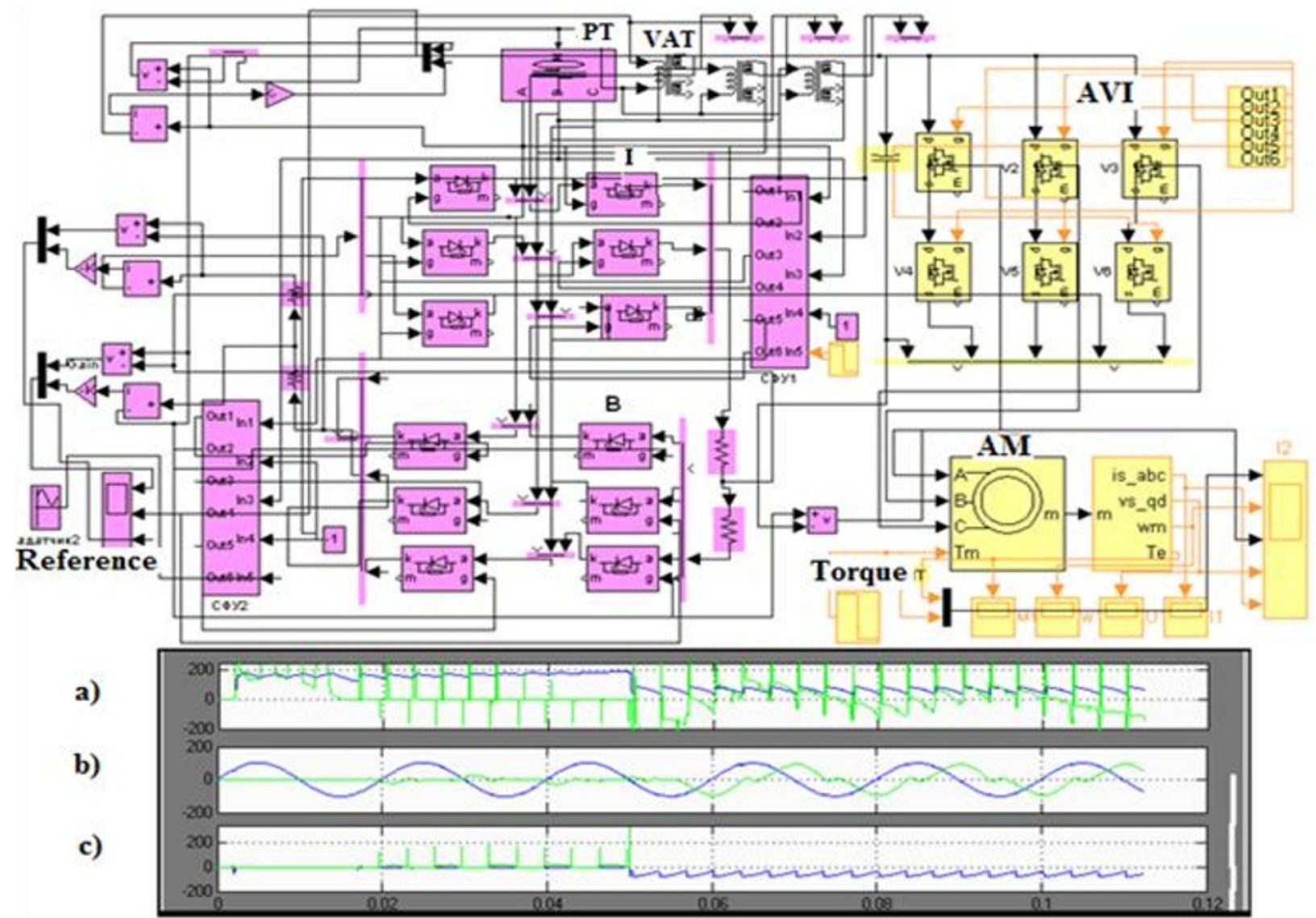

Fig. 2. Computer model of the version of the electric drive with the R/I-unit, equipped with a volt-adding autotransformer (VAT), below the voltage and current curves: a) the output circuit of the block R/I, b) the network input c) the equalization circuit. 
reactors in a reverse converter requires the introduction of an additional voltage-adding transformer (VAT) into the power circuit. Shown in Fig.2 curves of voltage and current output circuit R/I- unit (a), network input (b) and buffer circuit (c) illustrate the operation of this unit in the rectifier (at intervals of $t \leq 0.05$ c.), inverter (on the interval $t \geq 0.05 \mathrm{c}$ ) modes. The results of the simulation confirm the possibility of a reactor-free version of a reversible converter with a volt-add autotransformer. It can be seen that the solution actually leads to a decrease the equalizing current in the rectifier mode and a certain increase in this current in the inverter mode. Nevertheless, a high power of autotransformer VAT (710 kVA) up to $45 \%$ of the power transformer (1600 $\mathrm{kVA}$ ) in a working installation, making the solution economically unjustified, and therefore requires a search for less expensive execution of RFC in non-reactor version.

\subsection{Electric drive in direct drive design}

Mutual flows of electric power in the structure of a multi-motor electric drive require taking into account the influence of the common power bus of inverters and the mutual energy influence of electric drives (see Fig .1).

The mode of consumption or recovery in the RFC scheme is presented by the sign of the active power in the DC link. As shown in [2,13-15], the implementation of AVI on keys with two-way conductivity makes a part of the circuit a link of the constant voltage direction (LCVD). Allowing the network voltage to be sinusoidal, it is possible to analyze the mutual influence of electric drives according to the substitution scheme in Fig.3. One power supply for all $\mathrm{R} / \mathrm{I}$ inverters makes it possible to consider their voltage level and shape the same.

Therefore, the main reason for the energy interaction of drives in a multi-motor structure is the equalizing current of the

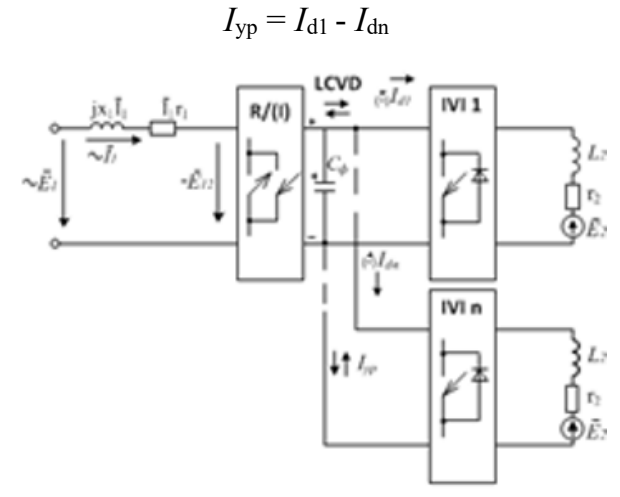

Fig. 3. Simplified equivalent circuit of a multi-motor electric drive on the basis of the and voltage inverters $\mathrm{AVI}_{1} \ldots \mathrm{AVI}_{\mathrm{n}}$. LCVD - Link of constant voltage direction); IVI 1 - IVI $n$ Independent (Autonomous) voltage inverters; R(I) (Rectifier Invertor); $\mathrm{I}_{1} \mathrm{r}_{1}, \mathrm{jx}_{1} \mathrm{I}_{1}$ - voltage drawdown on the input circuit; $E_{1}, E_{2}$ - input and output of the EMF; $E_{12}-E M F$ at the input of the rectifier; $\mathrm{r}_{2}, \mathrm{~L}_{2}$ - active-inductive load at the output of the inverter; $\mathrm{C}_{\phi}-$ filter capacity.

From the LCVD diagram in Fig.3, b it can be seen that in schemes based on AVI, the appearance of an equalizing current is possible in cases of operation of neighboring drives in different energy modes, and its closure occurs along the circuits that pass the capacitor $\mathrm{C}_{\mathrm{f}}$. During the simulation, it was expected to obtain a current discharge of the capacitor and, accordingly, a decrease in voltage ripples in the LCVD link, as shown in [2]. o test this assumption, a model of a two-motor electric drive is used (Fig.4) on two inventorof IVI1 and IVI2.This uses pulse-width control of the output voltage and frequency. The rectifier is made unmanaged, and the inverter is made on fully controlled fans to completely eliminate short circuits [16-19]. The presence of the LCVD filter $\mathrm{C}_{\mathrm{f}}$ provides smoothing of the voltage and reactive current circuit and locking of diodes of rectifier blocking current phase-to-phase short circuit at intervals

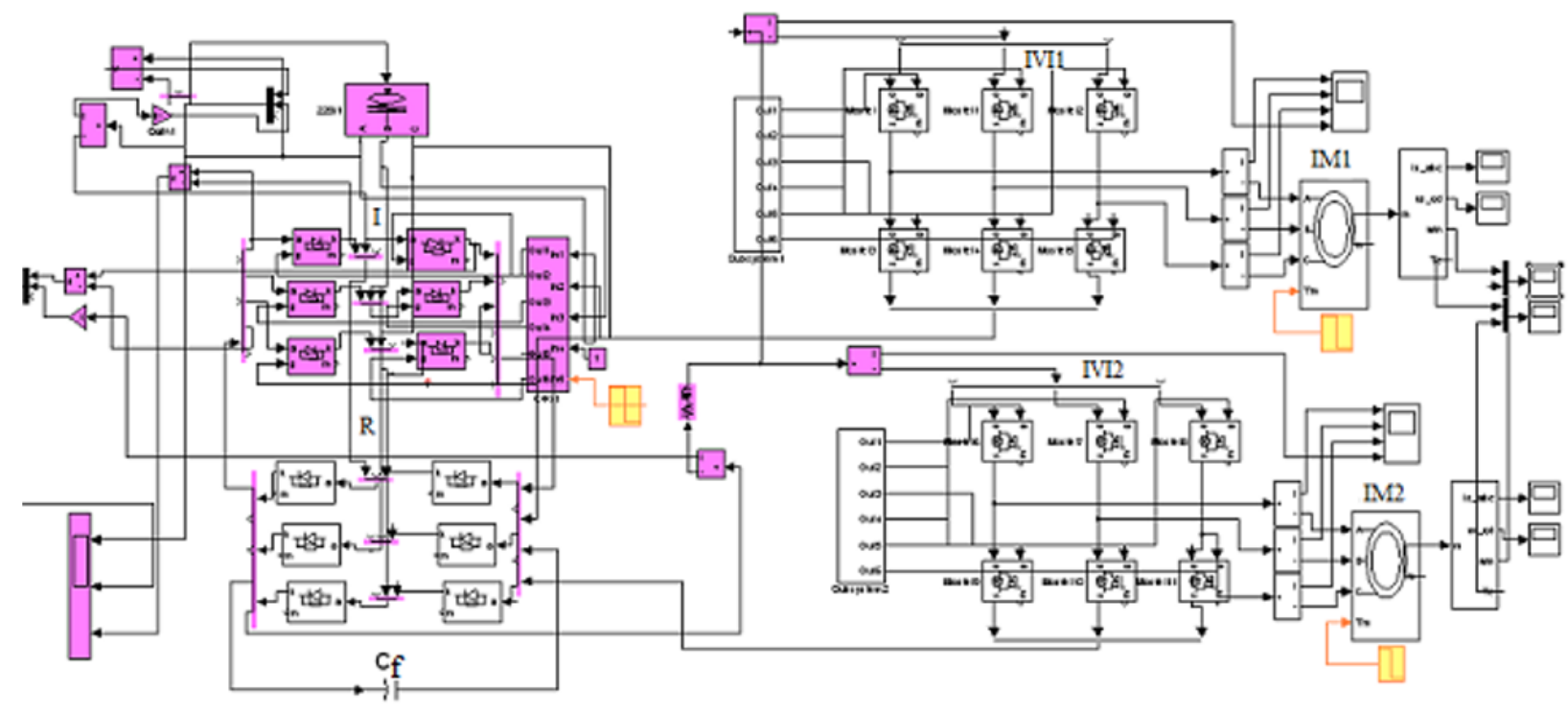

Fig. 4. Computer model of a twin-motor electric drive made by the system R-I-IVI-IM $+\mathrm{C}_{\mathrm{f}}$ : IVI (Independent (autonomus) voltage inverter), IM (Induction motor), R(I) (Rectifier - Invertor), $\mathrm{C}_{\mathrm{f}}$ (Capacity of filter). 
a)

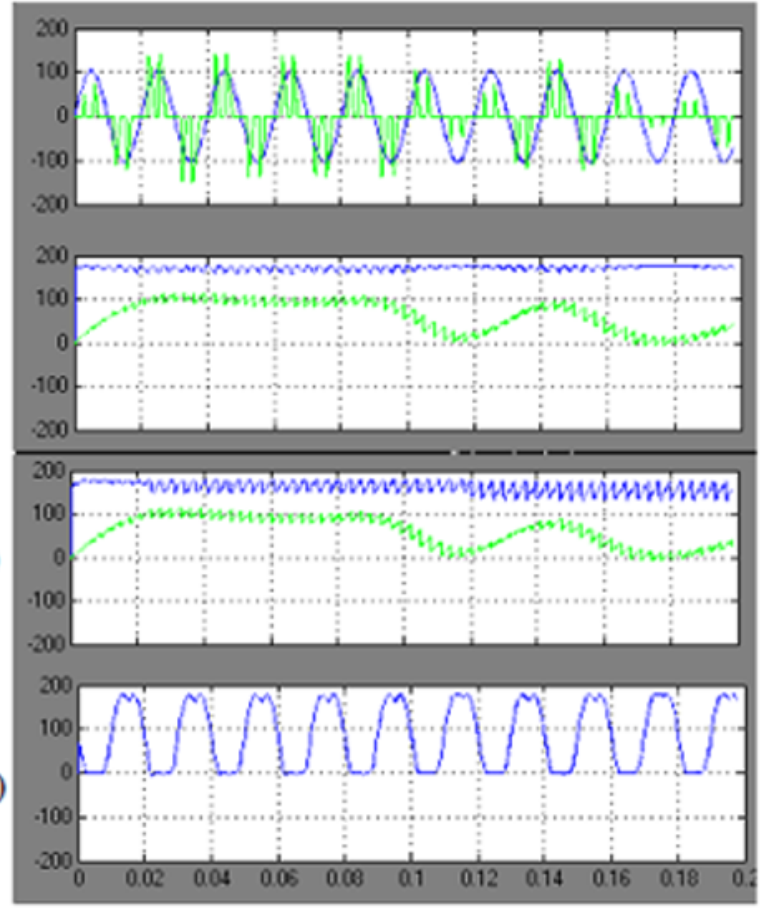

e)

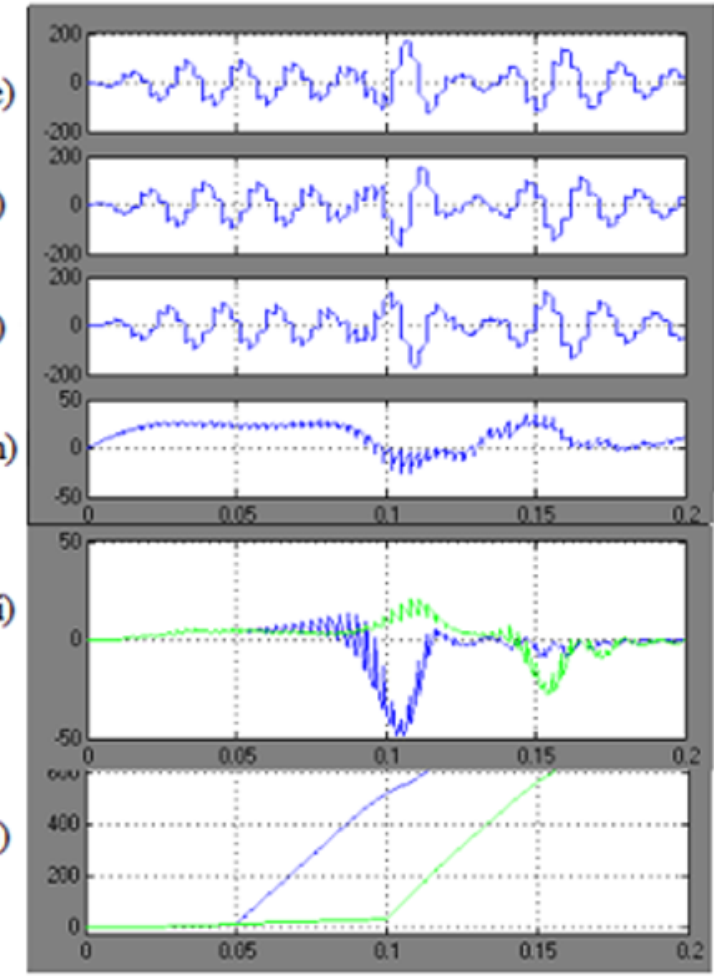

Fig. 5. The results of modeling the Electric drive in direct drive design : a - phase voltage and current of the network input; $b$ rectified voltage and current in the link LCVD at the common input of inverters; c - voltage on one of the keys of the block B/I; $\mathrm{f}, \mathrm{g}, \mathrm{h}$ - currents of the stator windings AD1; i,j - curves of the moment and speed of motor.

of simultaneous operation of the valves blocks I and R. In Fig. 5 the results of the simulation are presented. The electric drive was started at idle with further translation of $\mathrm{AM}_{1}$ and $\mathrm{AM}_{2}$ at moments $\mathrm{t}=0.05 \mathrm{sec}$. and $\mathrm{t}=0.1 \mathrm{sec}$. in regenerative braking mode by applying a torque to the shaft. For comparison, braking was performed when the inverter I was switched off and on. As it can be seen from the curve of Fig. 5, b., the transfer of AM2 at the moment $\mathrm{t}=0.1 \mathrm{sec}$. to the generator mode, along with an increase in the voltage level of the capacitor, led to a noticeable decrease in the resulting current at the input of the inverter AVI1 (Fig. 5, a).

$$
I_{\mathrm{d} 1}=I_{\mathrm{d} 2}-I_{\mathrm{yp}}
$$

Repeating this experiment with the inverter turned on, made it possible to stabilize the capacitor voltage at a lower level (see Fig. 5, b).

\section{Conclusions}

The presented variants of electric drive schemes based on RFC with a volt-adding transformer and RFC in a non-reactive version allow implementing the multiengine electric drive system as part of cord lines for tire production, as well as production lines containing electric drives, which can work with mutual energy influence on each other.. The circuits generally meet the requirements for technological electric drives as part of a cord line for energy recovery of the braking drive with energy transfer in the power supply chain of drive inverters powered by a common DC bus without the use of equalizing reactors. The implementation of a common DC bus in this aspect is the point of power supply and interaction of inverters, will reduce energy costs and increase the network-wide power factor. In addition, the presented results indicate a reduction in capital investment in the reconstruction of multi-motor drives due to the rejection of individual unmanaged rectifiers, each of which is both the cause of additional power losses and the cause of nonlinear distortion of the network voltage [20].

\section{References}

[1] S.N. Sidorov, Active converters of direct type on diode-transistor modules, Electrical Motorering 4 (2004)

[2] R. Ganiev, Reversible frequency converters in the composition of multimotor electric drives, IOP Conference Series: Materials Science and Engineering 643, International Scientific Electric Power Conference, Saint Petersburg, Russian Federation, IOP Conf. Ser.: Mater. Sci. Eng. 643, 012068 (23-24 May 2019)

[3] J.E. Valdez-Resendiz, J.C. Mayo-Maldonado, A. Llamas-Terres, J.C. Rosas-Caro, Quadratic boost converter based on stackable switching stage, IET Power Electronics 11, 8 (2018)

[4] R. Ganiev, Cordline multi-motor electric drive with energy recovery, E3S Web of Conferences 178, 9 July 2020, High Speed Turbomachines and 
Electrical Drives Conference, HSTED 2020, Prague, Czech Republic, 162052, 01023 (14-15 May 2020)

[5] T. Anish, A. Gopinath, G. Shiny, M.R. Baiju, A direct method for generating optimum sequence of switching vectors for multilevel inverters, EPE Journal, European Power Electronics and Drives Journal 24, 2 (2014)

[6] S.N. Sidorov, Control algorithms of two-operation valves in transducers with direct connection, Electrical Motorering 5 (2001)

[7] A. Rehaoulia, H. Rehaoulia, F. Fnaiech, Output voltage quality analysis of three-phase multilevel inverters, Electrical Motorering (Archiv für Elektrotechnik) 100, 2 (2018)

[8] A. Dendouga, R. Abdessemed, M.L. Bendaas, Active and reactive powers control of a doubly-fed induction generator fed by matrix converter, EPE Journal (European Power Electronics and Drives Journal) 19, 1 (2009)

[9] S. Zambou, R. Nuessl, F.M. Azeutsap, S.S. Zekeng, J.M. Ndjaka, B. Magunje, S.D. Walton, E.O. Jonah, M. Harting, D.T. Britton, Switching alternating current (ac) using a fully screen-printed current-driven transistor, IET Power Electronics 11, 1 (2018)

[10] R.N. Ganiev, N.I. Gorbachevsky, V.N. Dmitriev, S.N. Sidorov, Russian patent no. 2444834, Method for controlling a two-link frequency Converter, Publ. IN BI 5 (2012)

[11] R.N. Ganiev, S.N. Sidorov, Russian patent no. 2461115, Two-link frequency Converter with lockable valves, Publ. IN BI 5 (2012)

[12] A.M. Airabella, G.G. Oggier, L.E. Piris-Botalla, G.O. García, C.A. Falco, C. Ramos, A. Martins, A. Carvalho, Semi-conductors faults analysis in dual active bridge dc-dc converter, Active filtering of dfig stator and rotor current harmonics caused by distorted stator voltages, European Power Electronicsand Drives Journal 21, 1, 43-54 (2011)

[13] N. Al-Sheakh Ameen, A.A. Naassani, R.M. Kennel, Design of a digital system dedicated for electrical drive applications, EPE Journal (European Power Electronics and Drives Journal) 20, 4 (2010)

[14] M. Cacciato, A. Consoli, G. Scarcella, G. Scelba, Indirect maximum torque per ampere control of induction motor drives, EPE Journal (European Power Electronics and Drives Journal) 18, 4, 34-41 (2008)

[15] P. Záskalický, Mathematical model of a five-phase voltage-source pwm-controlled inverter, Electrical Motorering (Archiv für Elektrotechnik) 99, 4 (2017)

[16] K. Bernacki, Z. Rymarski, Electromagnetic compatibility of impedance source inverters, Elektronika ir Elektrotechnika 23, 3 (2017)
[17] G. Joksimovic, A. Binder, Additional no-load losses in inverter-fed high-speed cage induction motors, Electrical Motorering (Archiv für Elektrotechnik) 86, 2 (2004)

[18] N. Prabaharan, K. Palanisamy, Analysis of cascaded h-bridge multilevel inverter configuration with double level circuit, IET Power Electronics 10, 9 (2017)

[19] I. Nagy, J. Hamar, B. Buti, Dual channel resonant dc-dc converter family, EPE Journal (European Power Electronics and Drives Journal) 17, 3 (2007)

[20] S.N. Sidorov, R.N. Ganiev, System of frequencycurrent control of an electric drive based on lockable valves, Drive technology 1 (2011) 